\title{
Revisão dos gêneros Lachaerus e Clavidesmus (Coleoptera, Cerambycidae, Lamiinae, Onciderini)
}

\author{
Adriano José Giorgi ${ }^{1, \uparrow} \&$ Miguel A. Monné2 (D)
}

\begin{abstract}
1. Universidade Federal do Pará, Altamira, PA, Brasil
2. Departamento de Entomologia, Museu Nacional, Universidade Federal do Rio de Janeiro, Quinta da Boa Vista, São Cristóvão, $20940-040$ Rio de Janeiro, RJ, Brasil. (monne@uol.com.br)

$\dagger$. In memoriam. O presente artigo é resultado da dissertação de mestrado de Adriano José Giorgi defendida em 1998 no Departamento de Zoologia do Instituto de Biociências da Universidade de São Paulo. Em decorrência de terem passado 20 anos da defesa, foi necessário atualizar o texto. A publicação deste artigo é uma homenagem ao querido colega, professor do Campus de Altamira da Universidade Federal do Pará falecido em 27 de abril de 2018.
\end{abstract}

Recebido 11 maio 2018

Aceito 23 novembro 2018

Publicado 06 dezembro 2018

DOI 10.1590/1678-4766e2018044

urn:Isid:zoobank.org:pub:F241A288-C210-47AD-8BF6-39A4F9A39E86

\begin{abstract}
A revision of the genera Lachaerus and Clavidesmus (Coleoptera, Cerambycidae, Lamiinae, Onciderini). The revision is presented based on external and internal morphology; the Brazilian species are redescribed. The male characters of Clavidesmus are presented for the first time. New synonyms proposed: Orteguaza lichenigera Lane, 1958 junior synonym of Clavidesmus metallicus (Thomson, 1868). New combinations: Clavidesmus rubigineus Dillon \& Dillon, 1949 and Clavidesmus monnei Giorgi, 1998 to Lachaerus Thomson, 1868. New country record is reported: Lachaerus fascinus (Audinet-Serville, 1835) for Argentina. The Onciderini genera that share the swollen condition of the third antennomere could be separated in two groups: (1) Lachaerus and Clavidesmus, by the presence of a swollen antennomere in both sexes; (2) Eudesmus Audinet-Serville, 1835, Psyllotoxus Thomson, 1868, Oncideres Audinet-Serville, 1830, Taricanus Thomson, 1868 and Periergates Lacordaire 1872, by the presence of a swollen antennomere only in males.
\end{abstract}

KEYWORDS. Neotropical region, keys, taxonomy.

RESUMO. Neste estudo é apresentada a revisão dos gêneros Lachaerus Thomson, 1868 e Clavidesmus Dillon \& Dillon, 1945 (Cerambycidae, Lamiinae, Onciderini). As espécies brasileiras são redescritas com base na morfologia externa e interna. Chaves para identificação de espécies e ilustrações são fornecidas. Os caracteres masculinos de Clavidesmus são apresentados pela primeira vez. Como resultados, são estabelecidas as sinonímias entre Orteguaza lichenigera Lane, 1958 e Clavidesmus metallicus (Thomson, 1868). Novas combinações: Clavidesmus rubigineus Dillon \& Dillon, 1949 e Clavidesmus monnei Giorgi, 1998 são transferidas para Lachaerus. Novo registro de distribuição: Lachaerus fascinus (Audinet-Serville, 1835) para Argentina. Os gêneros de Onciderini que compartilham o engrossamento do antenômero III podem ser separados em dois grupos: (1) Lachaerus e Clavidesmus, que apresentam o terceiro antenômero nos dois sexos engrossados e (2) Eudesmus Audinet-Serville, 1835, Psyllotoxus Thomson, 1868, Oncideres AudinetServille, 1830, Taricanus Thomson, 1868 e Periergates Lacordaire 1872, com o terceiro antenômero engrossado somente nos machos.

PALAVRAS-CHAVE. Região Neotropical, chaves, taxonomia.

A tribo Onciderini é representada por 80 gêneros e 549 espécies, com distribuição nas regiões Neotrópica e Neártica (MonNÉ, 2018). Caracteriza-se pelo conjunto de caracteres: corpo cilíndrico e robusto, antenas curtas, pernas curtas e robustas, coxas globosas, fêmures clavados, cavidades coxais anteriores fechadas e cavidades coxais médias abertas (Dillon \& Dillon, 1945).

Entre as tribos consideradas próximas, Apomecynini foi a mais citada (LACORDAIRE, 1872; Dillon \& Dillon, 1945; LANE, 1958). A presença de cavidades mesocoxais fechadas diferencia os Apomecynini Neárticos dos Onciderini (LiNSLEY \& CHEMSAK, 1985), entretanto, esta condição não pode ser atribuída aos Apomecynini neotropicais. A retractibilidade da cabeça utilizada por LACORDAIRE (1872) como caráter válido para diferenciá-las foi desconsiderada por LANE (1958), que apontou para Onciderini ambas as condições, cabeça retrátil e não retrátil.

Ainda que sejam tribos bem estabelecidas dentro de Lamiinae, até hoje não foram apontados caracteres exclusivos que assegurassem sua condição monofilética, o que determina instabilidade em seus sistemas de classificação. Dillon \& Dillon (1945) citaram o hábito de postura em que fêmeas, através de cortes circulares, utilizam suas mandíbulas para serrarem o galho onde serão colocados os ovos (BAUCKE, 1958, 1961; BONDAR, 1956; MARINONI, 1969; AmANTE et al., 1976) - como característica exclusiva de Onciderini, entretanto apenas a biologia de poucas espécies de importância econômica é conhecida.

O engrossamento do terceiro antenômero não é condição exclusiva de Onciderini. Em Apomecynini, 
esta condição aparece em Ischioloncha Thomson, 1860, Xylomimus Bates, 1865, Symperga Lacordaire, 1872, Prosenella Lane, 1959 e Orteguaza Lane, 1958. Até serem transferidos por BREuning (1961) para Apomecynini, esses gêneros constituíam o grupo neotropical da tribo Ischiolonchini Lacordaire, 1872.

A presença de Ischioloncha Thomson fora da tribo Onciderini havia sido contestada por BATES (1885), que considerava esse gênero próximo de Eudesmus AudinetServille, 1835. Xylomimus, descrito pelo mesmo autor, também em Onciderini, foi posteriormente transferido por Dillon \& Dillon (1945) para Ischiolonchini.

Embora estivesse implícito pelo fato dos gêneros Clavidesmus e Lachaerus terem sido propostos a partir de espécies descritas em Eudesmus, a proximidade entre os gêneros ainda não havia sido comentada. Provavelmente isto se deve ao fato de Clavidesmus ter sido descrito com base num exemplar fêmea, a ausência de exemplares macho não permitiu que Dillon \& Dillon (1946) constatassem a semelhança de maior relevância existente entre Clavidesmus e Lachaerus, o engrossamento do terceiro antenômero em ambos os sexos, condição única entre os Onciderini.

Estudos sobre a sistemática de Onciderini são escassos e restringem-se basicamente à descrição de novos táxons; assim, não há nenhuma proposta de relacionamento filogenético para a tribo. THOMSON (1868) elaborou a única proposta de agrupamento supragenérico para a tribo, separando-a em dois grupos de acordo com o formato dos élitros, triangulares em "Hypsiomitae" e subparalelos em "Oncideritae". A proposta foi adotada por LACORDAIRE (1872) e desconsiderada por Dillon \& Dillon (1945).

Alguns gêneros de Onciderini apresentam o terceiro antenômero fortemente engrossado; Dillon \& Dillon (1945, 1946) conferiram importante valor taxonômico à forma desse antenômero e relacionaram Eudesmus Audinet-Serville, 1835, Psyllotoxus Thomson, 1868, Lachaerus Thomson, 1868 e Clavidesmus Dillon \& Dillon, 1945, devido ao formato "elíptico" dessa estrutura. A condição engrossada caracteriza também o terceiro antenômero de Taricanus Thomson, 1868 e Periergates Lacordaire, 1872, que apresentam, entretanto, formato cilíndrico. Essa condição é também observada nos machos de algumas espécies de Oncideres.

O engrossamento do antenômero III em ambos os sexos diferencia Lachaerus e Clavidesmus dos demais gêneros citados anteriormente, onde esta condição é exclusivamente masculina.

Giorgi (1998) sugeriu dois grupos de espécies em Clavidesmus com base no formato e na posição dos olhos, no formato do primeiro e do terceiro antenômeros e na coloração das antenas. Diferenciou C. monnei e C. rubigineus das demais espécies brasileiras do gênero (C. chicae, $C$. heterocerus, C. indistinctus e C. metallicus). Apesar de apresentarem padrão de colorido muito semelhante ao das outras espécies, a situação de C. monnei e C. rubigineus em Clavidesmus parece questionável, considerando que as condições atribuídas por GIORGI (1998) a estas espécies ocorriam também em Lachaerus fascinus.
Histórico. Thomson (1868) propôs Lachaerus para Eudesmus seminivorus Buquet, 1852; os caracteres arrolados pelo autor para justificar a transferência foram: pernas curtas, olhos divididos e tarsômeros 1 e 2 grossos e alongados.

Dillon \& Dillon $(1945,1946)$ descreveram Clavidesmus para abrigar Eudesmus heterocerus Buquet, 1852 e E. metallicus Thomson, 1868. O gênero proposto foi justificado pelos caracteres: a posição dos olhos em relação à margem da fronte, relevo do pronoto, comprimento das antenas em relação ao comprimento do corpo, comprimento do antenômero III em relação ao escapo, formato da fronte e do antenômero III nas fêmeas e a coloração. Os caracteres dos machos não foram apresentados uma vez que os autores utilizaram para descrever o gênero a fêmea de Eudesmus heterocerus.

Nesta mesma revisão, Dillon \& Dillon $(1945,1946)$ redescreveram Lachaerus, sem mencionar a relação entre os dois gêneros, que se evidencia de forma indireta por ter sido ambos relacionados a Eudesmus.

Dillon \& Dillon $(1949,1952)$ descreveram respectivamente Clavidesmus rubigineus de Santa Catarina e C. indistinctus da Bahia.

Breuning (1961) descreveu Clavidesmus columbianus proveniente da província de Darién, Panamá.

MonNÉ \& MARTins (1974) propuseram a sinonímia entre Eudesmus fascinus Audinet-Serville, 1835 e E. seminivorus Buquet, 1852.

Giorgi (1998) descreveu Clavidesmus monnei e C. chicae, respectivamente de Minas Gerais e São Paulo. Pela posição e formato dos olhos, pelo aspecto do escapo e do antenômero III e pela cor das antenas, identificou dois agrupamentos para o gênero. $O$ primeiro caracterizado pelos olhos fortemente separados da margem da fronte, os lobos oculares separados, pelo menos, por duas fileiras de omatídios, o terceiro antenômero em forma de bulbo, e os antenômeros ímpares, exceto o XI, unicolores. Incluiu C. chicae, C. heterocerus, C. indistinctus e C. metallicus. O segundo foi caracterizado pelos olhos bem próximos da margem da fronte, os lobos oculares separados por estreito istmo, desprovido de omatídios, antenômero III piriforme nos machos e todos os antenômeros bicolores a partir do IV. Inclui C. monnei e C. rubigineus.

Julio et al. (2000) citaram os holótipos de Clavidesmus chicae e C. monnei depositados no Museu Nacional, Rio de Janeiro, Brasil.

NeARns \& TaVakilian (2012) propuseram a sinonímia entre Orteguaza Lane, 1958 e Clavidesmus Thomson, 1868 e transferiram Orteguaza lichenigera Lane, 1958 para Clavidesmus.

Audureau (2012) publicou Clavidesmus rogueti do Peru, holótipo depositado em sua coleção privada.

NEARns et al. (2013) disponibilizaram chave pictórica para identificação de gêneros da tribo Onciderini.

NeARns et al. (2014) figuraram o holótipo de Lachaerus fascinus (Audinet-Serville, 1835), depositado no British Museum (Natural History), Londres, Inglaterra. 
NeARns \& TAVAKILIAN (2015) ilustraram os holótipos de Clavidesmus heterocerus (Buquet, 1852), C. metallicus (Thomson, 1868) e Lachaerus seminivorus (Buquet, 1852), depositados no Muséum National d'Histoire Naturelle, Paris, França.

Nearns \& Santos-Silva (2016) publicaram Clavidesmus egeri do Peru, holótipo depositado no United States National Museum, Smithsonian Institution, Washington, DC, Estados Unidos da América.

NEARns \& MaIER (2016) figuraram o holótipo de Clavidesmus indistinctus Dillon \& Dillon, 1952, depositado no Field Museum of Natural History, Chicago, Estados Unidos da América.

\section{MATERIAIS E MÉTODOS}

Dissecção. Os métodos utilizados para dissecção e diafanização das terminálias seguem MARQUES \& NAPP (1996).

Terminologia. Para a venação alar, MARINONI \& Almeida (1983) e para o metendosternito, Crowson (1938, 1944).

Instituições mencionadas no texto: AAPC, Coleção Privada de Alain Audureau, França; AMNH, American Museum of Natural History, Nova York, Estados Unidos da América; FMNH, Field Museum of Natural History, Chicago, Illinois, Estados Unidos da América; MNHN, Muséum National d'Histoire Naturelle, Paris, França; MNRJ, Museu Nacional, Universidade Federal do Rio de Janeiro, Rio de Janeiro, Brasil; SMTD, Staatliches Museum fur Tierkunde, Dresden, Alemanha; USNM, National Museum of Natural History, Washington, D. C., Estados Unidos da América.

\section{RESULTADOS E DISCUSSÃO}

\section{Lachaerus Thomson, 1868}

Lachaerus ThOmson, 1868:71; LACORDAIRE, 1872:683; Dillon \& Dillon, 1946:295; MonNÉ, 2005:561 (cat.); MonNÉ, 2012:111.

Espécie-tipo: Eudesmus seminivorus Buquet, 1852 (designação original) [= Eudesmus fascinus AudinetServille, 1835].

Macho. Cabeça tão larga quanto o protórax, moderadamente oblíqua. Margem posterior dos lobos oculares superiores distantes da margem anterior do pronoto. Olhos finamente facetados, lobos inferiores oblongoovalados, conectados aos lobos superiores por estreito istmo desprovido de omatídios. Lobos superiores estreitos, com aproximadamente a metade dos inferiores.

Fronte transversa, trapezoidal, com as margens curvas, estreitando-se anteriormente, plana entre os tubérculos antenais, com um distinto tubérculo a cada lado do centro ou lisa. Lobos inferiores do mesmo comprimento que as genas. Tubérculos antenais contíguos na base. Clípeo sinuoso na margem distal, com a metade da largura do labro, este transverso com bordos laterais retos, bordo anterior sinuoso. Mandíbulas robustas, curvas desde a base, lisas a partir da metade apical, fase lateral externa triangular, bordo cortante não denteado. Maxilas com basistipe não fusionado ao dististipe; gálea cilíndrico-capitada, alcançando o ápice do segundo artículo. Lacínia bem desenvolvida, com franja compacta de cerdas ao longo das margens apical e lateral. Palpos com quatro artículos, artículo basal curto, com a metade do comprimento do segundo, os três distais subiguais em comprimento, segundo e terceiro cônicos, o distal cilíndrico, agudo no ápice. Lábio com mento transverso. Lígula envolvendo o artículo basal e aproximadamente metade do segundo artículo dos palpos, bordo apical levemente chanfrado no centro. Palpos triarticulados, artículo basal curto, menor que a metade do segundo artículo, segundo e terceiro subiguais em comprimento, segundo clavado, o distal agudo no ápice.

Antenas ultrapassam o ápice dos élitros aproximadamente no antenômero IX, franjadas nos antenômeros II e III por pelos longos, com o tegumento bicolor (L.fascinus) ou unicolor (L. monnei e L. rubigineus). Escapo robusto, curto, apenas alcança a margem anterior do pronoto, pouco mais longo que o IX, aplanado na superfície ventral, levemente enrugado na base e comprimido dorsoventralmente no ápice. Antenômero III gradativamente engrossado em direção ao ápice, onde atinge a maior largura, comprimento igual a uma vez e meia o comprimento do escapo. Antenômero IV cilíndrico, pouco mais longo que $\mathrm{o}$ V. Antenômeros V-X gradativamente decrescendo para a extremidade. Antenômero XI pouco maior que o X, curvado a partir do meio, com ápice agudo (L.fascinus) ou curvado a partir do $1 / 4$ apical, com extremidade arredondada (L. monnei, L. rubigineus).

Protórax levemente transverso, apenas estreitado na base, margem anterior marcadamente sinuosa, tubérculos laterais diminutos, disco do pronoto sem tubérculos, liso (L. monnei, L. rubigineus) ou com um distinto tubérculo na extremidade lateral anterior do disco (L.fascinus). Escutelo transverso, semicircular no ápice. Processo prosternal regularmente curvo, mais estreito anteriormente, alargado em sentido posterior. Processo mesosternal pouco mais largo que o prosternal, de lados subparalelos. Proendosternito semicoriáceo, bem desenvolvido, de aspecto triangular. Metendosternito com pedúnculo estreito, lâminas laterais bem desenvolvidas, horizontais, destacadas dos braços anteriores, tendões bem aproximados.

Élitros fortemente convexos, levemente expandidos após o meio, com abrupto declive no quarto apical: úmeros estreitos, apenas mais largos que o protórax, levemente projetados em pequeno tubérculo obtuso.

Pernas robustas, subiguais em comprimento; fêmures clavados, comprimento apenas maior que as tíbias, estas expandidas para o ápice. Tarsômeros I, II, e III subiguais em comprimento, com pilosidade longa e densa, tarsômero $\mathrm{V}$ igual à soma dos quatro precedentes. Profêmures bruscamente clavados a partir do terço basal, mais robustos que os médios e 
posteriores; lados subparalelos no terço basal com rugas bem marcadas. Mesotíbias com calosidade levemente projetada no bordo superior.

Abdome com esternitos V e VI subiguais em largura, mais estreitos que os esternitos III e IV; esternito VII mais largo que longo, semiesférico, com ápice marcadamente sinuoso (L.fascinus), ou levemente sinuoso (L. monnei e $L$. rubigineus); tergito VII levemente sinuoso na extremidade.

Fêmea. Tubérculos antenais menos projetados que nos machos. Antenas apenas ultrapassam o meio dos élitros. Antenômero III engrossado a partir do meio, com franja de cerdas densas na metade apical. Profêmures subiguais aos demais, sem rugas na base. Abdome com os quatro primeiros esternitos subiguais em comprimento. Esternito VII de comprimento maior que os precedentes, 3,5 vezes mais longo do que largo, ápice truncado com impressão triangular mediana.

Comentários. O gênero Lachaerus era constituído por uma espécie (L.fascinus), que tem como característica o forte estreitamento que ocorre na junção dos lobos oculares, caráter que está presente também em Taricanus. A presença desse estreitamento em duas espécies de Clavidesmus ( $C$. rubigineus Dillon \& Dillon, 1949 e C. monnei Giorgi, 1998), foi observada por Giongi (1998), que sugeriu a existência de dois grupos de espécies para o gênero. Além do estreitamento, essas espécies foram caracterizadas por apresentarem olhos próximos à margem da fronte; escapo comprimido no ápice; tegumento bicolor a partir do VI antenômero e nos machos, terceiro antenômero engrossado em direção ao ápice. Com exceção da cor do tegumento das antenas, os demais caracteres eram também compartilhados por Lachaerus fascinus, ao contrário das demais espécies de Clavidesmus, que apresentavam junção dos olhos com pelo menos duas fileiras de omatídios, olhos fortemente destacados da margem da fronte, escapo arredondado no ápice, terceiro antenômero engrossado desde a base nos machos e antenômeros com tegumento unicolor.

É importante salientar a extrema semelhança de coloração que existe entre L. rubigineus e C. heterocerus. Ambas as espécies possuem o corpo predominantemente coberto por pubescência amarela, na cabeça ornamentada por uma faixa diagonal e nos élitros por uma larga faixa pós-mediana e duas manchas no quarto distal formadas por pubescência castanha.

Lachaerus fascinus, por outro lado, possui coloração distinta, com élitros e metatíbias bicolores, além disso, uma ampla região do pronoto sem pelos e a presença de pelos eretos no ápice dos élitros, diferenciam esta espécies de todas as demais.

Lachaerus diferencia-se de Clavidesmus por possuir: margens da fronte curvas; tubérculos antenais contíguos na base; mandíbulas curvadas a partir da base; lobos oculares conectados por estreito istmo desprovido de omatídios; franja antenal presente apenas no antenômero III; escapo comprimido dorsoventralmente no ápice; élitros com declive abrupto no quarto apical; pelos longos densamente distribuídos nos tarsômeros. Nos machos, fronte plana entre os tubérculos antenais; ápice dos mesmos projetado lateralmente; terceiro antenômero engrossado gradativamente em direção ao ápice; na fêmea, terceiro antenômero densamente franjado.

\section{Chave de identificação para as espécies de Lachaerus}

1. Tegumento dos antenômeros unicolor; tufos de pelos eretos no quarto apical dos élitros; pubescência branca, aveludada, cobrindo completamente a metade basal dos élitros; fronte com um par de pequenas projeções entre os tubérculos antenais; macho com antenômero XI curvado a partir do meio, agudo no ápice; pronoto glabro no disco; tubérculo na extremidade látero-anterior do disco do pronoto; élitros com as margens posteriores internas separadas. Brasil (Bahia, Espírito Santo, Minas Gerais, Rio de Janeiro, São Paulo, Paraná), Argentina (Tucumán). (Fig. 1).

..L. fascinus (Audinet-Serville, 1835)

- Tegumento dos antenômeros bicolor a partir do IV; élitros sem tufos de pelos eretos e sem pubescência branca; fronte lisa entre os tubérculos antenais; macho com antenômero XI curvado a partir do quarto distal, arredondado no ápice; pronoto totalmente coberto por pelos; pronoto sem tubérculos no disco; élitros com as margens posteriores internas contíguas.

2. Tegumento preto; pernas semiglabras; pubescência preta formando faixas na cabeça e no pronoto; sem pubescência vermelha. Brasil (Minas Gerais). (Fig. 2).

..L. monnei (Giorgi, 1998)

- Tegumento castanho; pernas completamente cobertas por pubescência; pubescência vermelha concentrada na cabeça e no protórax, sem pubescência preta. Brasil (Espírito Santo, São Paulo, Paraná, Santa Catarina). (Fig. 3) ...L. rubigineus (Dillon \& Dillon, 1949)

\section{Lachaerus fascinus (Audinet-Serville, 1835)}

(Fig. 1)

Eudesmus fascinus Audinet-Serville, 1835:82; Strauch, 1861:136; Thomson, 1868:69; Lameere, 1884:93 (distr.); Dillon \& Dillon, 1946:304; NeARns et al., 2014:262, figs. 3a, b (designação de lectótipo). Lachaerus fascinus MonnÉ \& MARTIns, 1974:27 (syn.); Monné, 2005:561 (cat.); Monné et al., 2010:249 (distr.).

Eudesmus seminivorus BUQUET, 1852:345; NEARNS \& TAVAKILIAN, 2015:11, figs 19a, b (holótipo).

Lachaerus seminivosus THOMson, 1868:71; 1878:18 (tipo).

Lachaerus seminivorus Aurivillius, 1923:350 (cat.); Dillon \& Dillon, 1946:296, pl. 17, fig. 3; ViANA, 1972:357 (distr.).

Localidade-tipo: Brasil. (BMNH). Distribuição: Brasil (Bahia, Minas Gerais, Espírito Santo, Rio de Janeiro).

Localidade-tipo: Brasil. (MNHN).

Tegumento castanho-avermelhado. Corpo (Fig. 1) parcialmente coberto por pubescência branca, aveludada, castanho-avermelhada e castanho-escura, disposta em tufos de pelos eretos no quarto apical dos élitros. Antenas e fêmures parcialmente glabros. Pubescência branca, aveludada, cobre pouco mais que a metade basal dos élitros, toda a 
superfície ventral do meso- e metatórax, coxas, terço basal dos fêmures, metade apical das metatíbias e extremidade basal do antenômero III. A mesma pubescência forma mancha apical na margem dorsal das pro- e mesotíbias e uma tênue faixa diagonal no quarto apical dos élitros. Esparsa ao longo do bordo posterior do protórax e nas pernas. Pubescência castanho-avermelhada cobrindo cabeça, protórax, quarto apical dos élitros e lados dos esternitos abdominais. Pubescência castanho-escura nas tíbias e em forma de pequenas manchas no quarto apical dos élitros.

Tegumento das antenas castanho-avermelhado, parcialmente coberto por pubescência castanho-escura, mais concentrada no antenômero III, demais antenômeros parcialmente glabros. Antenômeros I e II brilhantes, IV ao XI opacos. Pubescência esbranquiçada cobre a metade apical dos antenômeros IV, VI, VIII e X e o quarto apical dos antenômeros V, VII, IX e XI.

Fronte com um par de pequenos tubérculos entre os tubérculos antenais, que são aguçados e proeminentes nos machos. Lábio com lígula esparsamente coberta no lado interno, forma uma estreita faixa lateral em direção ao mento. Antenômero XI curvado a partir do meio, agudo no ápice nos machos.

Pronoto glabro no disco, com distinto tubérculo na extremidade látero-anterior. Élitros com as margens pósterointernas separadas. Esternito VII com ápice marcadamente sinuoso.

Dimensões, em mm, $\widehat{\partial} / q$ : Comprimento total 8,914,7/10,3-16,9; comprimento do protórax 1,5-3,0/1,8-30; comprimento dos élitros 6,2-9,5/7,1-12,0; largura umeral 2,8-4,8/3,1-5,3; maior largura do protórax 2,1-4,0/2,2-3.8.

Material examinado. BRASIL, Bahia: Itamaraju, , X.1987, O. Roppa col. Espírito Santo: Baixo Guandu, ㅇ, X.1971, P. C. Elias col.; Colatina, 2ㅇ, XI.1970, B. Silva col., 3 đ̃, X.1976, B. Silva col.; Barra do São Francisco (Córrego do Itá), 2 , XI.1954, W. Grossmann col.; Linhares,

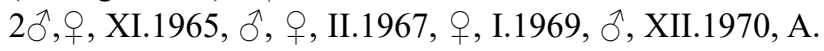
Maller col. ㅇ, XII.1967, , XII.1971, ô, 4ㅇ, XI.1973, ô, XII.1973, B. Silva col., 2 , , XI.1966, $2 \curvearrowright$,, , XII.1969, + , XI.1970, S. A. Fragoso col. Minas Gerais: Teófilo Otoni, §, XI.1972, S. P. Nascimento col. Rio de Janeiro: Rio de Janeiro (Corcovado), ふૈ, 18.X.1970, Alvarenga \& Seabra col.; (Rocinha), + , X.1965, G. Andrade col. São Paulo: Peruíbe, , XII.1940, H. Zellibor col. Paraná: Arapongas, đૈ, XI.1951, đૈ, II.1962, A. Maller. ARGENTINA, Tucumán: San Miguel de Tucumán, ㅇ, II.1952, ô, II.1955, Bosq col. (Todos MNRJ). Tucumán.

Novo registro de distribuição para país, ARGENTINA,

Comentários. Lachaerus fascinus apresenta grande variação morfométrica entre indivíduos, como pode ser observado nas dimensões. Os caracteres mais evidentes para identificação preliminar são: ausência de pubescência no disco do pronoto, coloração e tufos de pelos eretos no quarto apical dos élitros.

\section{Lachaerus monnei (Giorgi, 1998), comb. nov.}

\section{(Fig. 2)}

Clavidesmus monnei GIORGI, 1998:2, fig. 1; Julio et al., 2000:34 (holótipo); Monné, 2005:544 (cat.); Nearns \& TaVakilian, 2012:17, fig. 7h; Monné \& Monné, 2016:70 (holótipo).

Localidade-tipo: Brasil, Minas Gerais: Estação Ecológica de Piratininga (Lagoa Três Marias, $18^{\circ} 22^{\prime} \mathrm{S}$, 4519'W). (holótipo, MNRJ). Distribuição: Brasil (Minas Gerais).

Tegumento preto. Corpo (Fig. 2) parcialmente coberto por pubescência amarela e preta, pernas e antenas semiglabras, brilhantes. Pubescência amarela cobrindo completamente os esternitos torácicos. Essa pubescência recobre a cada lado do meio, estreita faixa longitudinal desde o vértice, entre os tubérculos antenais, até a margem anterior do protórax; na altura da junção dos lobos oculares, uma faixa diagonal descendente, a partir da margem posterior dos lobos oculares superiores, alargando-se em direção ao protórax; na fronte, uma estreita faixa paralela ao epistoma, desde a margem da fronte até a margem anterior do protórax, sem atingilo; discreta faixa longitudinal na face interna dos meso- e metafêmures. Pubescência preta cobre a metade apical do mesepímero, e a região basal e média do mesepisterno, concentrada na superfície média dos esternitos abdominais III e VII e nas extremidades laterais dos esternitos IV, V, VI e VII. Essa pubescência forma uma estreita faixa centrolongitudinal a partir da fronte, entre os tubérculos laterais, até a margem anterior do protórax; a cada lado do centro, uma larga faixa longitudinal desde os lobos oculares superiores até a margem anterior do protórax; faixa longitudinal descendente, a partir da extremidade inferior da margem posterior dos olhos, alargando-se em direção ao protórax. Nos élitros, faixa indistinta pós-mediana, estendendo-se em direção ao ápice, da margem para a sutura, no quarto distal, duas manchas, uma circular no centro de cada élitro e outra longitudinal, paralela à margem externa.

Antenas parcialmente cobertas por pubescência castanha, densamente concentrada no antenômero III, demais antenômeros semiglabros, I e II brilhantes, IV-XI opacos, pubescência amarela cobre ventralmente a base de escapo e do antenômero III, pubescência esbranquiçada a partir do antenômero IV. Nos machos, antenômero XI curvado a partir do quarto apical, arredondado no ápice.

Fronte lisa entre os tubérculos antenais, estes com projeções pouco desenvolvidas nos machos.

Pronoto completamente coberto por pubescência, sem tubérculos. Élitros com as margens póstero-internas contíguas. Esternito VII levemente sinuoso no ápice.

Dimensões em mm, ô. Comprimento total, 12,8; comprimento do protórax, 1,6; comprimento dos élitros, 8,2 ; maior largura do protórax, 2,8; largura umeral, 4,1.

Material examinado. BRASIL, Minas Gerais: Piratininga (Estação Ecológica de Piratininga, Lagoa Três 
Marias, $\left.18^{\circ} 22^{\prime} \mathrm{S}, 45^{\circ} 19^{\prime} \mathrm{W}, 560 \mathrm{~m}\right),{ }^{\lambda}, 10 . X I .1996$, Doug Yanega col. (Holótipo, MNRJ).

Comentários. Lachaerus monnei assemelha-se a $L$. rubigineus (Dillon \& Dillon, 1949) e diferencia-se pelos caracteres: tegumento preto; pernas semiglabras; pubescência preta forma faixa na cabeça e no pronoto; pubescência vermelha ausente.

\section{Lachaerus rubigineus (Dillon \& Dillon, 1949), comb. nov.}

(Fig. 3)

Clavidesmus rubigineus Dillon \& Dillon, 1949:11; MonnÉ, 2005:544 (cat.); Nearns \& TaVakilian, 2012:17, fig. 7i.

Localidade-tipo: Brasil, Santa Catarina: Corupá. (AMNH). Distribuição: Brasil (Espírito Santo, São Paulo, Paraná, Santa Catarina).

Tegumento castanho-escuro. Corpo (Fig. 3) coberto por pubescência amarela e castanha. Pubescência amarela densamente concentrada nas laterais do protórax, inferiormente ao tubérculo lateral, cobre completamente as pernas, os esternitos torácicos e abdominais. Essa pubescência forma a cada lado do meio, uma estreita faixa longitudinal, desde a fronte, entre os tubérculos anteriores, até a margem anterior do protórax; na altura do istmo ocular, faixa diagonal descendente, a partir da margem posterior dos olhos, alargando-se em direção ao protórax, sem alcançá-lo; na fronte, faixa estreita paralela ao epistoma, desde a margem da fronte até a borda anterior do protórax, sem alcançá-lo. Pubescência vermelha entremeada na amarela. Pubescência castanha formando estreita faixa centro-longituinal a partir da fronte, entre os tubérculos antenais, até a margem anterior do protórax; a cada lado do centro, larga faixa longitudinal, desde os lobos oculares superiores até a margem anterior do protórax; faixa diagonal descendente, a partir da extremidade inferior da margem posterior dos olhos, alargando-se em direção à margem do protórax, sem atingi-lo; na metade basal de cada élitro, uma mancha centro-longitudinal, que não atinge os úmeros nem a sutura; na altura do declive apical, larga faixa diagonal pós-mediana estendendo-se em direção ao ápice a partir da margem até a sutura elitral; no quarto apical duas manchas indistintas, uma circular no centro de cada élitro, outra longitudinal, paralela à margem externa.

Antenas parcialmente cobertas por pubescência castanha, densamente concentrada nos três primeiros antenômeros; antenômeros IV-XI semiglabros, opacos; pubescência amarela cobre ventralmente a metade basal dos antenômeros I e III; pubescência esbranquiçada a partir do antenômero IV. Antenômero XI curvado a partir do quarto apical, nos machos arredondado no ápice.

Fronte lisa entre os tubérculos antenais, estes com projeção pouco desenvolvida nos machos. Pronoto completamente coberto por pubêscencia, sem tubérculos. Élitros com margens póstero-internas contíguas. Esternito levemente sinuoso no ápice.
Dimensões, em mm, $3 /$ / . Comprimento total, 14,216,7/13,6-15,3; comprimento do protórax, 2,7-2,9/2,7-33; comprimento dos élitros, 10,3-12,2/9,1-10,4; maior largura do protórax, 3,5-3,9/3,3-3,8; largura umeral, 4,6-5,5/4,6-5,4.

Material examinado. BRASIL, Espírito Santo: Colatina, + , XI.1971, A. Silva col.; Conceição da Barra (Pedro Canário), + , X.1976, E. dos Santos col.; Linhares,

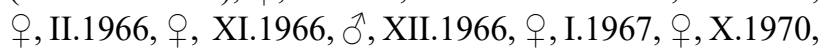

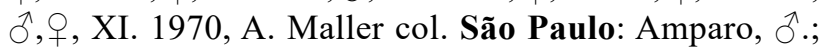
Marília,, , XI.1945, H. Zellibor col. Paraná: Santa Mariana, ㅇ, XI.1951, H. Zellibor col. Santa Catarina: Corupá, đ̂, 1940, ô, II.1943, A. Maller col. (Todos MNRJ).

Comentários. A distribuição e concentração da pubescência vermelha variam de acordo com a distribuição geográfica. Os exemplares mais meridionais apresentam distribuição mais ampla e maior concentração de pubescência vermelha no corpo.

\section{Clavidesmus Dillon \& Dillon, 1946}

Clavidesmus Dillon \& Dillon, 1946:293; Monné, 2005:543 (cat.); MonNé, 2012:109; Nearns \& TaVakilian, 2012:17 (syn.). Espécie tipo: Eudesmus heterocerus Buquet, 1852 (designação original).

Orteguaza Lane, 1958:10; Breuning, 1971:264; MonNÉ, $2005: 302$ (cat.); MonNÉ, 2012:87. Espécie tipo: Orteguaza lichenigera Lane, 1958 (designação original).

Macho. Cabeça tão larga quanto o protórax, moderadamente oblíqua, com a margem posterior dos lobos oculares superiores distantes da borda anterior do pronoto. Fronte transversa, trapezoidal, côncava entre os tubérculos antenais. Genas apenas mais longas que os lobos oculares inferiores. Tubérculos antenais separados na base, proeminência bem desenvolvida, com ápice projetado superiormente. Clípeo com a metade da largura do labro, sinuoso na margem distal. Labro transverso, bordos laterais ligeiramente retos, bordo anterior sinuoso. Mandíbulas robustas, curvadas e lisas a partir do meio, bordo cortante não denteado. Maxilas com basistipe não fusionado ao dististipe. Gálea cilíndrico-capitada, alcança o ápice do segundo artículo. Lacínia bem desenvolvida. Palpífero e cardo com pelos longos, esparsos. Palpos com quatro artículos, os três últimos subiguais em comprimento. Lábio com mento transverso. Lígula envolve o artículo basal e cerca da metade do segundo artículo dos palpos. Palpos triarticulados, artículo basal curto, segundo e terceiro subiguais em comprimento.

Olhos pequenos, finamente facetados, bem separados. Lobos inferiores oblongo-ovalados, estreitados inferiormente, fortemente destacados da margem da fronte, conectados com os lobos superiores por duas ou três fileiras de omatídios. Lobos superiores estreitos, com cerca da metade da largura dos inferiores.

Antenas ultrapassam o ápice dos élitros aproximadamente no antenômero IX, inteiramente franjadas a partir do antenômero II por pelos longos e eretos, mais concentrados nos antenômeros III e XI. Escapo robusto, gradualmente engrossado para o ápice, alcança a margem 
anterior do pronoto, aplanado na superfície ventral, levemente enrugado na base, arredondado no ápice. Antenômero III igualmente engrossado em ambas extremidades, atingindo a maior largura no meio. Antenômero IV cilíndrico, estreito, comprimento e largura apenas maiores que o V. Antenômero XI pouco maior que $\mathrm{o} X$, sinuoso no quinto distal, agudo no ápice.

Protórax levemente transverso, subcilíndrico, pouco mais estreito na base, reto na margem anterior; tubérculos laterais diminutos, disco liso. Processo prosternal regularmente curvo, alargando-se em sentido posterior. Processo mesosternal pouco mais largo que o prosternal, lados subparalelos.

Élitros fortemente convexos, levemente expandidos após o meio, com suave declive no quarto distal. Úmeros estreitos, pouco mais largos que o protórax, ligeiramente projetados em pequeno tubérculo obtuso, oblíquo. Margens posteriores internas contíguas.

Pernas robustas, subiguais em comprimento; fêmures clavados, com comprimento pouco maior que as tíbias, que são subiguais em comprimento aos tarsos. Mesocoxas com tubérculo diminuto. Profêmures abruptamente clavados a partir do terço basal, distintamente mais robustos que os fêmures médios e posteriores; terço basal com rugas transversais bem marcadas; mesotíbias com calosidade apenas projetada no bordo superior. Protarsos com tarsômeros I e II mais largo que longos. Tarsômero $\mathrm{V}$ com comprimento igual à soma dos quatro precedentes.

Abdome com esternitos IV, V, e VI subiguais em largura, mais estreitos que o III, que é tão largo quanto o VII, este marcadamente sinuoso no ápice; tergito VII levemente sinuoso na extremidade distal.

Fêmea. Fronte plana entre os tubérculos antenais, estes menos projetados que nos machos. Antenas apenas ultrapassam o meio dos élitros; antenômero III engrossado a partir do meio, com franja de pelos esparsos na metade distal. Profêmures subiguais aos meso- e metafêmures, sem rugas na base. Esternito VII de comprimento maior que os precedentes, 3,5 vezes mais longo do que largo; ápice distal truncado, com impressão triangular mediana.

Comentários. Os seguintes caracteres são comuns para Clavidesmus e Lachaerus: fronte transversa, com olhos bem separados. Olhos pequenos, destacados da margem da fronte. Lobos oculares inferiores subiguais ao comprimento da gena. Antenas encurtadas a partir do quarto antenômero. Escapo apenas alcança a margem anterior do pronoto. Terceiro antenômero engrossado em ambos os sexos. Protórax transverso, apenas mais estreito posteriormente; disco do pronoto sem tubérculos no centro. Élitros simplesmente pontuados, fortemente convexos, expandidos após o meio, com declive distinto no quarto apical. Fêmures clavados; tíbias expandidas em direção ao ápice. Mesocoxas com tubérculo. Nos machos, terceiro antenômero esparsamente franjado. Profêmures abruptamente clavados a partir do terço basal. Nas fêmeas, comprimento dos antenômeros I-IV maior que o dos antenômeros V-XI.
Clavidesmus diferencia-se de Lachaerus por possuir margens da fronte retas; tubérculos antenais separados na base; mandíbulas curvadas a partir do terço basal; lobos oculares conectados por duas ou três fileiras de omatídios; franja antenal presente em todos os antenômeros a partir do segundo; escapo arredondado no ápice; élitros com suave declive no quarto distal; pelos longos esparsamente distribuídos nos tarsômeros. Nos machos, fronte côncava entre os tubérculos antenais; ápice dos tubérculos antenais projetado superiormente; antenômero III igualmente engrossado em ambas as extremidades; nas fêmeas, terceiro antenômero esparsamente franjado.

\section{Chave para identificação das espécies de Clavidesmus (exceto C. colombianus Breuning, 1961)}

1. Tegumento preto; em cada élitro duas linhas esbranquiçadas, a anterior pós-mediana, oblíqua da margem para a sutura, a posterior no quinto apical, mais reduzida, paralela à sutura. Bolívia. C. funerarius (Lane, 1958)

- Outro padrão de coloração.. $\ldots 2$

Élitros com duas manchas esbranquiçadas, a anterior circular nos dois terços anteriores e a posterior ocupando o quarto distal. Peru ................. egeri Nearns \& Santos-Silva, 2016

- Outro padrão de colorido ......................................................

3. Pernas semiglabras, brilhantes; faixa centro-longitudinal com pubescência amarela desde o vértice até a metade posterior dos élitros; faixa lateral amarela contínua, da cabeça até o último segmento do abdome. Brasil (Amazonas, Mato Grosso), Guiana Francesa, Peru ......... ..C. metallicus (Thomson, 1868)

- Pernas completamente cobertas por pubescência; faixa centro-longitudinal, quando presente, apenas alcança o escutelo; faixa lateral ausente ............................................... 4

4. Corpo recoberto por pubescência castanho-escura, que forma uma mancha triangular a cada lado do vértice e uma mancha na face interna dos meso- e metafêmures; uma pequena mancha glabra, brilhante no centro do disco do pronoto. Brasil (Bahia, Espírito Santo) .

C. indistinctus Dillon \& Dillon, 1952

- Pubescência castanho-escura ausente; pronoto completamente revestido por pubescência..

. .5

5. Tegumento castanho; com duas faixas elitrais pós-medianas estreitas; cabeça completamente coberta por pubescência amarela, sem ornamentação. Brasil (São Paulo). (Fig. 4)...... C. chicae Giorgi, 1998

- Outro padrão de coloração

6. Cabeça coberta por pubescência amarela, ornamentada por faixas central e lateral de pubescência castanha; metade distal dos élitros com duas faixas largas, oblíquas de margens indefinidas. Brasil (Espírito Santo, Rio de Janeiro). (Fig. 5) .................................. heterocerus (Buquet, 1852) - Cabeça coberta por pubescência amarela, sem faixa de pubescência castanha; metade distal dos élitros com duas faixas oblíquas, estreitas, de margens nitidamente definidas. Peru (Fig. 6)............................ rogueti Audureau, 2012 


\section{Clavidesmus chicae Giorgi, 1998}

(Fig. 4)

Clavidesmus chicae Giorgi, 1998:3, fig. 2; Julio et al., 2000:34 (holótipo); Monné, 2005:543 (cat.); NeARns \& TAVAKILIAN, 2012:17, fig. 7a; Monné \& Monné, 2016:70 (holótipo).

Localidade-tipo: Brasil, São Paulo: Botucatu. (MNRJ). Distribuição: Brasil (São Paulo).

Tegumento castanho. Corpo completamente coberto por pubescência amarela e castanha. Pubescência amarela cobre completamente cabeça, pernas, esternitos torácicos e abdominais e metade inferior do protórax, forma, nos élitros, duas faixas diagonais pós-medianas estreitas: (1) a primeira de comprimento maior e mais definida, estende-se em direção ao ápice a partir da margem externa até a sutura, (2) a segunda, paralela à primeira, mais apical e menor, não alcança a margem nem a sutura. Pubescência castanha restrita aos élitros e à metade superior do protórax, sem formar faixas ou manchas. Antenas parcialmente cobertas por pubescência castanha, densamente concentrada nos três antenômeros basais; antenômeros IV-XI semiglabros.

Dimensões, em mm, macho. Comprimento total, 16,3; comprimento do protórax, 2,5; comprimento dos élitros, 10,4; maior largura do protórax, 3,4; largura umeral, 4,9.

Material examinado. BRASIL, São Paulo: Botucatu, I.1968 (holótipo $\widehat{\jmath}$, MNRJ).

Comentários. Distingue-se das demais espécies de Clavidesmus pela seguinte combinação de caracteres: tegumento castanho; pernas completamente cobertas por pubescência, os fêmures por pubescência castanha; élitros sem faixa centro-longitudinal; pronoto completamente revestido por pubescência; cabeça com pubescência amarela, sem manchas de outra cor.

\section{Clavidesmus columbianus Breuning, 1961}

Clavidesmus columbianus BREUnING, 1961:333; MartíneZ, 2000:101 (distr.); Monné, 2005:544 (cat.); NEARns \& TAVAKILIAN, 2012:17, fig. 7b. (Material não examinado).

Localidade-tipo: Colômbia, Província Darién. (SMTD). Distribuição: Colômbia.

\section{Clavidesmus egeri Nearns \& Santos-Silva, 2016}

Clavidesmus egeri Nearns \& Santos-Silva, 2016:448, figs 9-12. (Material não examinado.)

Localidade-tipo: Peru, San Martín: Dept. Tarapoto, vic. Cordillera Escalera Lodge, 432 m. S 06²8'08.1”, W 076²1'16.4”. (USNM). Distribuição: Peru.

\section{Clavidesmus heterocerus (Buquet, 1852)}

(Fig. 5)

Eudesmus heterocerus BuQuet, 1852:344; THOMSON, 1868:69; 1878:18 (type); NEARns \& TAVAKILIAN, 2015:4, fig. 14a, b.

Clavidesmus heterocerus; Dillon \& Dillon, 1946:294, pl. 17, fig. 6; Viana, 1972:357 (distr.); Monné, 2005:544 (cat.); WAPPES et al., 2006:26 (distr.); NEARNS \& TAVAKILIAN, 2012:17, fig. 7d.

Localidade-tipo: Brasil. (MNHN). Distribuição: Brasil (Espírito Santo, Rio de Janeiro), Bolívia (Santa Cruz), Paraguai.

Macho. Tegumento preto. Corpo completamente coberto de pubescência amarela e castanha. Pubescência amarela cobre as pernas, os esternitos torácicos e abdominais, formando uma larga faixa centro-longitudinal desde o vértice, onde é mais estreita até o escutelo. Pubescência castanha forma uma faixa diagonal descendente a partir da extremidade inferior da margem posterior dos olhos, alargando-se em direção ao protórax; a cada lado do centro uma larga faixa longitudinal, de bordos mal definidos. No declive apical dos élitros essa pubescência forma uma faixa diagonal pós-mediana que se estende em direção ao ápice a partir da margem externa até a sutura; no quarto distal dos élitros, uma distinta mancha diagonal, apenas mais oblíqua que a faixa pós-mediana.

Antenas parcialmente cobertas por pubescência castanha, densamente concentrada nos antenômeros I a III. Antenômeros IV-XI semiglabros, opacos. Pubescência amarela cobre os $4 / 5$ basais do antenômero IV, metade basal dos antenômeros VI, VIII, X e XI e ventralmente, a metade anterior do III.

Lábio com lígula densamente coberta por pelos curtos na face interna.

Dimensões, em mm, $\widehat{\delta} / q$. Comprimento total, 18,8/18,9; comprimento do protórax, 3,4/3,4; comprimento dos élitros, 12,5/13,2; maior largura do protórax, 4,6/4,2, largura umeral, 6,3/6,2.

Material examinado. BRASIL, Espírito Santo: Linhares, 2ð, X .1965, ㅇ, XI.1965, 2ㅇ, XII.1966, 2ㅇ,

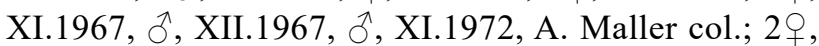
XI.1967, F. M. Oliveira col. Rio de Janeiro: Rio de Janeiro (Corcovado), o, 21.XI.1957, , XI.1961, , 12.XII.1962, ๆ, 30.XI.1966, 2q, 28.XI.1969, Seabra \& Alvarenga (Todos MNRJ).

Comentários. Diferencia-se das demais espécies de Clavidesmus, pela combinação de caracteres: pernas completamente cobertas por pubescência; faixa centrolongitudinal alcança apenas o escutelo; sem pubescência castanho-escura; pronoto completamente coberto por pubescência; faixa pós-mediana larga; cabeça coberta por pubescência amarela, ornamentada por faixas de pubescência castanha. 

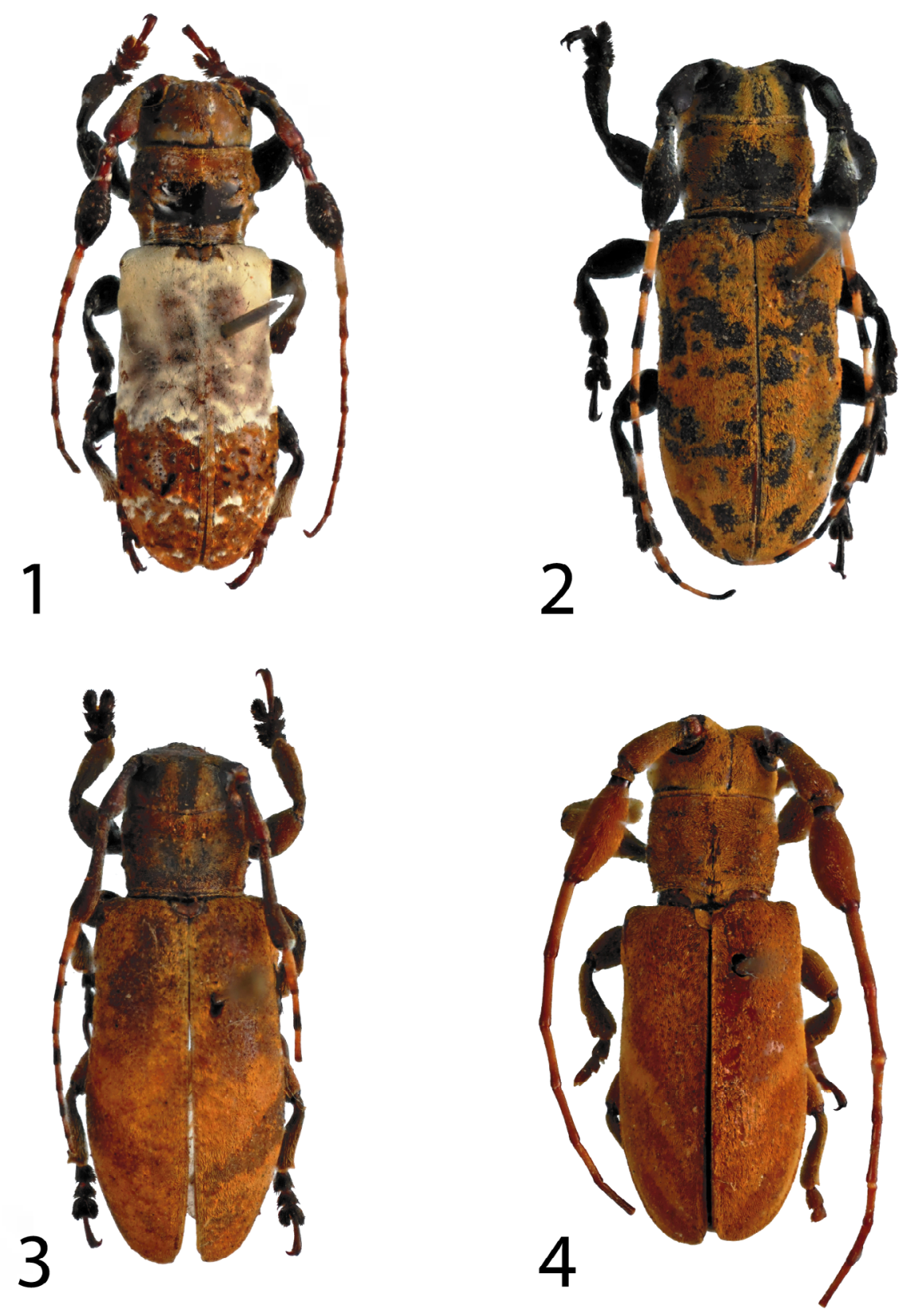

Figs 1-4: 1, Lachaerus fascinus (Audinet-Serville, 1835); 2, Lachaerus monnei (Giorgi, 1998), holótipo đ; 3, Lachaerus rubigineus (Dillon \& Dillon, 1949); 4. Clavidesmus chicae (Giorgi, 1998), holótipo 3 .

\section{Clavidesmus funerarius (Lane, 1958)}

Orteguaza funeraria LANE, 1958:13, fig. 2; BREUnING, 1971:265; MonNÉ, 2005:302 (cat.); WAPPES et al., 2006:25 (distr.); LiNGAFELTER et al., 2014:68, figs. 72w, x (holótipo).

Clavidesmus funerarius; NEARns \& TAVAKILIAN, 2012:17, fig. 7c.

Localidade-tipo: Bolívia, La Paz: Tumupasa. (USNM). Distribuição: Bolívia (La Paz).

Tegumento preto. Corpo completamente revestido por pubescência preta, cobrindo quase a totalidade da superfície corporal e pubescência amarela formando uma estreita faixa diagonal descendente, a partir da margem posterior dos olhos até a margem anterior do portórax; essa faixa conecta-se à faixa longitudinal que se estende da margem anterior à posterior do protórax; uma pequena mancha no centro do metepisterno; mancha triangular na extremidade posterior do metasterno; máculas laterais nos esternitos abdominais, mais concentradas no VII.

Nos élitros, a pubescência amarela forma: curta e estreita faixa sutural centro-longitudinal no terço basal; estreita faixa pós-mediana oblíqua da margem para a sutura, sem atingi-la; no quarto apical duas manchas em cada élitro, uma paralela e aproximada da margem e outra central.

Antenas parcialmente revestidas por pubescência predominantemente preta, densamente concentrada nos três primeiros antenômeros; IV-XI semi-glabros, opacos; pubescência esbranquiçada na base do escapo. 
Dimensões, em mm. + . Comprimento total, 19,5; maior largura do protórax, 5,0; largura umeral, 7,0.

Material examinado. BOLÍVIA, La Paz: Tumupasa, ㅇ, 1921-1922, W.M. Mann, Mulford Biological Expl. (Holótipo, USNM).

Comentários. Distingue-se das demais espécies de Clavidesmus por apresentar corpo predominantemente revestido por pubescência preta.

\section{Clavidesmus indistinctus Dillon \& Dillon, 1952}

Clavidesmus indistinctus Dillon \& Dillon, 1952:74; ChemsaK, 1977:174 (type); Monné, 2005:544 (cat.); Nearns \& TaVaKilian, 2012:17, fig. 7e; NeARns \& MaIER, 2016:4, figs. 6a, b (holótipo).

Localidade-tipo: Brasil, Bahia. (FMNH). Distribuição: Brasil (Bahia, Espírito Santo).

Tegumento preto. Corpo completamente coberto por pubescência amarela e castanho-escura, com pequena mancha glabra no centro do disco do pronoto. Pubescência amarela forma larga faixa longitudinal desde a margem posterior dos lobos inferiores até a margem anterior do protórax; estreita faixa centro-longitudinal desde o vértice até o escutelo. A cada lado do centro, superiormente ao tubérculo lateral, faixa estreita ao longo do protórax. Élitros, faixa indistinta diagonal pós-mediana estendendo-se da margem até a sutura. Pubescência semelhante cobre as pernas, e os esternitos torácicos e abdominais.

Pubescência castanho-escura distribuída em toda a superfície elitral, formando pequena mancha triangular atrás dos lobos oculares superiores; faixa longitudinal descendente, a partir da extremidade inferior da margem posterior dos olhos, alargando-se em direção ao protórax, sem alcançálo. A cada lado do pronoto estreita e mal delimitada faixa, desde a margem posterior dos lobos oculares superiores até a margem posterior do pronoto. No quarto apical dos élitros pubescência castanho-escura, disposta em duas manchas, uma circular central e outra alongada paralela à margem. Pubescência castanho-escura na face interna dos meso- e metafêmures.

Antenas parcialmente cobertas por pubescência predominantemente amarela, densamente concentrada nos três antenômeros basais; antenômeros IV-XI semiglabros, opacos; pubescência castanho-escura reveste a metade apical dos antenômeros IV, VI, VIII, X e XI e, ventralmente, o quinto distal do III.

Dimensões, em mm, $\hat{\jmath}$. Comprimento total, 16,4; comprimento do protórax, 2,7; comprimento dos élitros, 10,4; maior largura do protórax, 3,6; largura umeral, 5,0.

Material examinado. BRASIL, Espírito Santo: Linhares, đ̊, XI.1963, B. Silva col. (MNRJ).

Comentários. Diferencia-se das outras espécies de Clavidesmus pela seguinte combinação de caracteres: corpo ornamentado por pubescência castanho-escura; pernas pubescentes; mácula glabra e brilhante no centro do disco do pronoto.

\section{Clavidesmus metallicus (Thomson, 1868)}

(Fig. 7)

Eudesmus metallicus Thomson, 1868:70; 1878:12 (tipo); NeARns \& TAVAKILIAN, 2015:11, figs 15a, b (holótipo).

Clavidesmus metallicus; Dillon \& Dillon, 1946:295; TaVaKilian in Hequet, 1996:pl. 15, fig. 5; MonNÉ, 2005:544 (cat.); WapPes et al., 2006:26 (distr.); Nearns \& SWIFT, 2011:20 (distr.); Monné et al., 2012:43 (distr.); Nearns \& TaVakilian, 2012:17, fig. 7g; Morvan \& Roguet, 2013:29 (distr.); NeARns \& TAVAKILIAN, 2015:108 (distr.).

Orteguaza lichenigera LANE, 1958: 10, fig. 1; BREUNING, 1971: 264; MARTínez, 2000: 96 (distr.); TuRnBow et al., 2003: 21 (distr.); MonNÉ, 2005: 302 (cat.); Swift et al., 2010: 51 (distr.); Demez \& Touroult, 2011: 106 (distr.), syn. nov.

Clavidesmus lichenigerus NeARns \& TAVAKILIAN, 2012: 17, fig. 7f. Localidade tipo: Colômbia, Rastrojo, Rio Orteguaza. (AMNH).

Localidade-tipo: Cayenne. (MNHN). Distribuição: Honduras, Colômbia, Guiana Francesa, Venezuela, Equador, Brasil (Amazonas, Mato Grosso), Peru (Junin), Bolívia (Santa Cruz).

Tegumento vermelho escuro. Corpo (Fig. 7) parcialmente revestido por pubescência amarela e castanho-escura. Pubescência amarela forma longa faixa centro-longitudinal desde o vértice até o meio dos élitros. No vértice, a faixa é estreita e bem definida, alargando-se abruptamente a partir da margem anterior do protórax, com limites laterais mal definidos e encontrando-se, no meio dos élitros, com faixa diagonal, também de pubescência amarela, que se estende em direção à base, até atingir a margem externa dos élitros. Lateralmente, longa faixa longitudinal de pubescência amarela, estende-se desde a margem posterior dos lobos oculares inferiores até o último esternito abdominal, interrompida apenas no meio do metepisterno.

Pubescência castanho-escura forma, a cada lado do centro, larga faixa longitudinal, de lados mal definidos, que encobre os tubérculos laterais, desde a margen posterior dos lobos oculares superiores até a margem posterior do protórax; uma faixa transversal no centro do metepisterno. No declive apical dos élitros, a pubescência castanho-escura forma estreita faixa diagonal, da margem para o ápice, até a sutura; no quarto distal, próxima à margem, mancha semicircular bem definida.

Antenas parcialmente revestidas por pubescência castanho-escura, densamente concentrada no antenômero III; demais antenômeros semi-glabros, I e II brilhantes, IVXI opacos. Pubescência esbranquiçada cobre os $4 / 5$ basais do antenômero IV, metade basal dos antenômeros III, IV, VI, VIII, X e XI.

Dimensões, em mm, $\widehat{o}, q$. Comprimento total, 16,4/17,4; comprimento do protórax, 3,3/3,1; comprimento dos élitros, 11,2/12,1; maior largura do protórax, 3,9/4.1; largura umeral, 5,6/5,7.

Material examinado. BRASIL, Amazonas: Benjamin Constant, + , VII.1942, A. Parko col. Mato Grosso: Barra do 
Bugres, + , X.1988, B. Silva col. PERU, Junin: Sani Beni, đ̊, 2ㅇ, X.1935, §̊, X.1942, F. Woytkowski col. (Todos MNRJ).

Comentários. A combinação dos seguintes caracteres possibilita o reconhecimento de $C$. metallicus: tegumento vermelho; corpo ornamentado por pubescência castanho escura; pernas semi-glabras; faixa centro-longitudinal de pubescência amarela desde o vértice até a metade posterior dos élitros; faixa lateral contínua de pubescência amarela, da cabeça até e extremidade lateral da metacoxa; faixa pósmediana larga de pubescência amarela.
Clavidesmus rogueti Audureau, 2012

(Fig. 6)

Clavidesmus rogueti Audureau, 2012:62, figs. 1, 2.

Localidade tipo: Peru, Huanuco: Tingo María. (AACP). Distribuição: Peru.

Material examinado. PERU. Madre de Dios: $12 \mathrm{~km}$ E Mazuco, Pte. Amanapu, 1302'51'S, 70²0'55”W, 382 m, 18-22.VII.2012, R. Cavichioli, J. A. Rafael, A. P. M. Santos \& D. M. Takiya col.
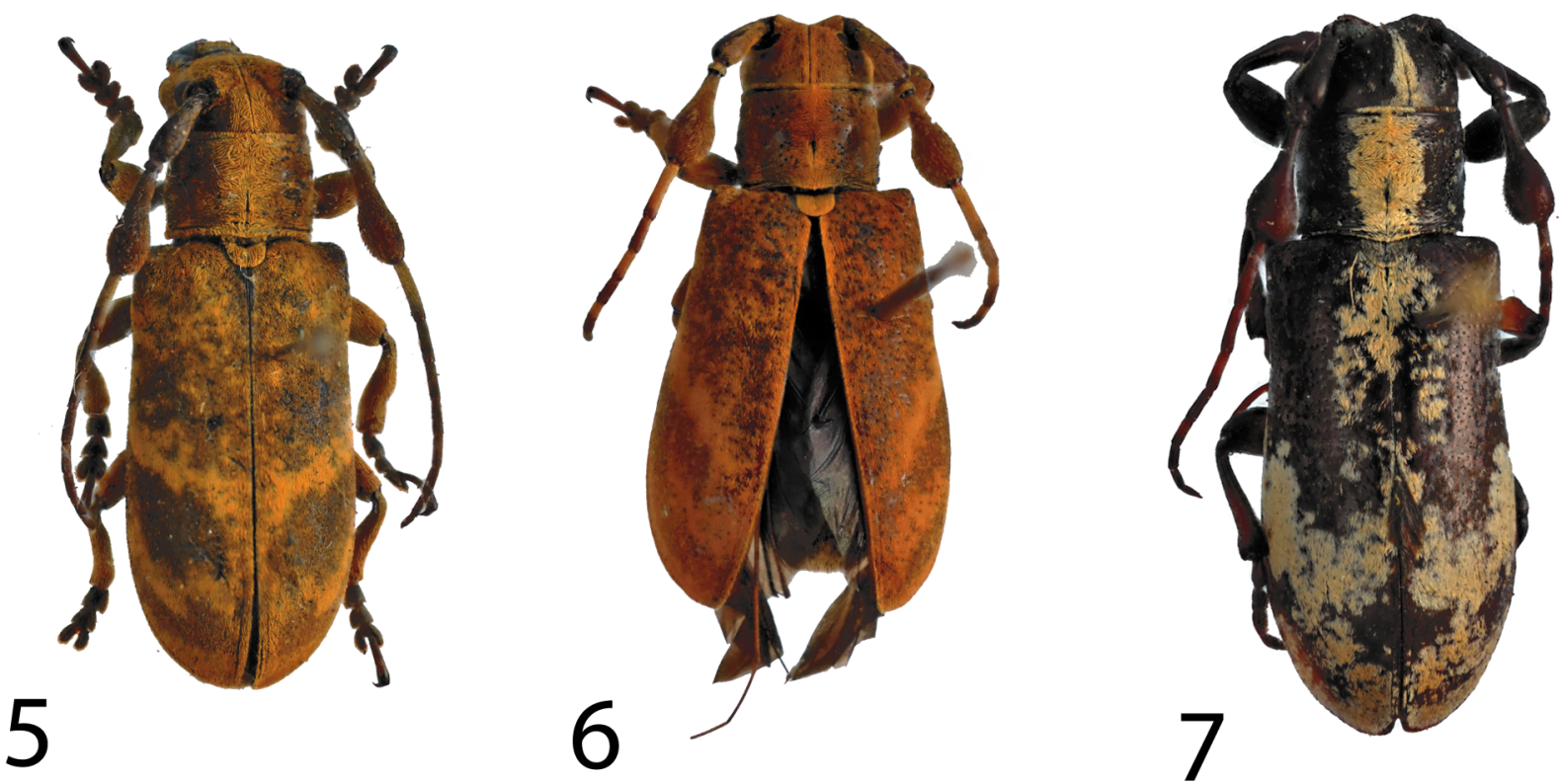

Figs 5-7: 5, Clavidesmus heterocerus (Buquet, 1852); 6, Clavidesmus rogueti Audureau, 2012; 7, Clavidesmus metallicus (Thomson, 1868).

\section{REFERÊNCIAS BIBLIOGRÁFICAS}

Amante, E.; Berlato, M. A.; Gessinger, G. I.; Didone, I. A. \& Rodrigues, I. C. 1976. Bioecologia do "serrador" da Acácia-negra, Oncideres impluviata (Germar, 1824) (Coleoptera, Cerambycidae) no Rio Grande do Sul. I. Etologia. Agronomia Sulriograndense 12(1):3-54.

Audinet-Serville, J. G. 1835. Nouvelle classification de la famille des longicornes (suite et fin). Annales de la Société Entomologique de France 4(1): 197-228.

Audureau, A. 2012. Notes sur les Onciderini du Pérou (Coleoptera, Cerambycidae, Lamiinae, Onciderini). Les Cahiers Magellanes 9:61-68.

Aurivillius, C. 1923. Coleopterorum Catalogus, pars 74, Cerambycidae: Lamiinae. Berlin, W. Junk, p. 323-704.

Bates, H. W. 1885. Biologia Centrali-Americana, Insecta, Coleoptera, suppl. to Longicornia. London 5:249-436.

BAUCKE, O. 1958. Biologia e contrôle do serrador da Acácia negra, Oncideres impluviata Germ. Pelotas, Escola de Agronomia Eliseu Maciel. 59p.

BAUCKE, O. 1961. Notas sôbre a biologia e o contrôle ao "Serrador" da Acácia negra. FIR 3(7):25-28.

Bondar, G. 1956. A biologia do gênero Oncideres e descrição de nova espécie. Longicornia 3:765-768.

Breuning, S. 1961. Neue Lamiiden aus dem Museum G. Frey (Col., Cerambycidae). Entomologischen Arbeiten aus dem Museum G. Frey 12:326-342.

Breuning, S. 1971. Révision des espèces américaines de la tribue des Apomecynini Lac. (Coleoptera, Cerambycidae). Entomologische Abhandlungen aus dem Staatliches Museum für Tierkunde 37(3):209-335
Buquet, J. B. L. 1852. Notice sur le genre Eudesmus, de l'ordre des coléoptères. Revue et Magasin de Zoologie 4(2):343-345.

ChemsaK, J. A. 1977. A list of types of Cerambycidae at the Field Museum of Natural History, Chicago (Coleoptera). The Coleopterists' Bulletin 31(2):173-179.

Crowson, R. A. 1938. The metendosternite in Coleoptera: a comparative study. Transactions of the Entomological Society of London 87(17):397-416

Crowson, R. A. 1944. Further studies on the metendosternite in Coleoptera. Transactions of the Entomological Society of London 94(2):273-310.

Demez, P. \& Touroult, J. 2011. Contribution à la connaissance des longicornes du Pérou I. 59 nouveaux signalements pour le pays (Coleoptera, Cerambycidae). Les Cahiers Magellanes 6:97-108.

Dillon, L. S. \& Dillon, E. S. 1945. The tribe Onciderini (Coleoptera: Cerambycidae). Part I. Scientific Publications of the Reading Public Museum 5:1-186.

Dillon, L. S. \& Dillon, E. S. 1946. The tribe Onciderini (Coleoptera: Cerambycidae). Part II. Scientific Publications of the Reading Public Museum 6:189-413.

Dillon, L. S. \& Dillon, E. S. 1949. Miscellaneous synonymy and new species among Lamiinae (Cerambycidae). American Museum Novitates 1388:1-13.

Dillon, L. S. \& Dillon, E. S. 1952. The tribe Onciderini. Supplementary notes. Annals of the Entomological Society of America 45:59-79.

Giorgi, J. A. 1998. Duas novas espécies de Clavidesmus Dillon \& Dillon, 1946 (Coleoptera, Cerambycidae, Lamiinae, Onciderini). Boletim do Museu Nacional Zoologia 394:1-4.

Julio, C. E. A.. Giongi, J. A. \& MonNÉ, M. A. 2000. Os tipos primários de Cerambycidae (Coleoptera) da coleção do Museu Nacional - Rio de Janeiro. Publicações Avulsas do Museu Nacional 84:1-54. 
Lacordaire, J. T. 1872. Histoire Naturelle des Insectes. Genera des Coléoptères, ou exposé méthodique et critique de tous les genres proposés jusqu'ici dans cet ordre d'insectes. Paris, Librairie Encyclopédique de Roret 9(2):411-930.

LAmeEre, A. A. 1884. Longicornes des voyages du Dr. E. Fromont au Brésil et a La Plata. Annales de la Société Entomologique de Belgique 28:102-104.

LANE, F. 1958. A new neotropical genus of Ischiolonchini (Coleoptera, Lamiidae). American Museum Novitates 1889:1-17.

Lingafelter, S. W.; Nearns, E. H.; Tavakilian, G. L.; Monné, M. A. \& Biondi, M. 2014. Longhorned Woodboring Beetles (Coleoptera, Cerambycidae and Disteniidae) Primary types of the Smithsonian Institution. Smithsonian Institution Scholarly Press, Washington D. C. 390 p.

LinsLey, E. G. \& ChemsaK, J. A. 1985. The Cerambycidae of North America. Part VII, No. 1. Taxonomy and classification of the subfamily Lamiinae, tribes Parmenini through Acanthoderini. University of California Publications in Entomology 102:1-258.

MarinONI, R. C. 1969. Sôbre a biologia e ontogenia de Oncideres dejeanii Thomson, 1868 (Coleoptera, Cerambycidae). Boletim da Universidade Federal do Paraná (Zoologia) 3(8): 193-210.

MarinONi, R. C. \& Almeida, L. M. 1983. Sobre a venação alar em Coccinellidae e Cerambycidae (Coleoptera). Revista Brasileira de Entomologia 27(3/4):267-275.

Marques, M. I. \& NAPP, D. S. 1996. Revisão e transferência para Rhopalophorini (Coleoptera, Cerambycidae) dos gêneros Coremia A.-Serville, 1834 e Merocoremia Marques, 1994. Revista Brasileira de Entomologia 40(3/4):379-423.

MartíneZ, C. 2000. Escarabajos longicórnios (Coleoptera, Cerambycidae) de Colombia. Biota Colombiana 1(1):76-105.

MonNÉ, M. A. 2005 Catalogue of the Cerambycidae (Coleoptera) of the Neotropical Region. Part II. Subfamily Lamiinae. Zootaxa 1023:1759 .

MonNÉ, M. A. 2012. Catalogue of the type-species of the genera of the Cerambycidae, Disteniidae, Oxypeltidae and Vesperidae (Coleoptera) of the Neotropical Region. Zootaxa 3213:1-183.

Monné, M. A. 2018. Catalogue of the Cerambycidae (Coleoptera) of the Neotropical Region. Part I. Subfamily Cerambycinae. Disponível em $<$ http://www.cerambyxcat.com>. Acessado em 02 maio 2018.

MonNÉ, M. A. \& Martins, U. R. 1974. Notas sinonímicas, observações e descrições em Cerambycidae (Coleoptera). Revista Brasileira de Entomologia 18(1):21-31.

Monné, M. A.; Nearns, E. H.; Carbonel Carril, S. H.; Swift, I. P. \& Monné, M. L. 2012. Preliminary checklist of the Cerambycidae, Disteniidae, and Vesperidae (Coleoptera) of Peru. Insecta Mundi 213:1-48.

Monné, M. A. \& Monné, M. L. 2016. Checklist of Cerambycidae (Coleoptera) primary types of the Museu Nacional, Rio de Janeiro, Brazil, with a brief history of the collection. Zootaxa 4110(1):1-90.

Monné, M. L.; Monné, M. A.; Martins, R. S.; Simões, M. V. P. \& Machado, V. S. 2010. Espécies de Cerambycidae (Insecta, Coleoptera) ocorrentes no Estado do Rio de Janeiro (Brasil). Arquivos do Museu Nacional 67(3-4):235-251.
Morvan, O. \& Roguet, J-P. 2013. Inventaire des Cerambycidae de Guyane (Coleoptera). Supplement au Bulletin de liaison d'ACOREP. France « Le Coleopteriste » 7:3-44.

Nearns, E. H. \& SwiFt, I. P. 2011. New taxa and combinations in Onciderin Thomson, 1860 (Coleoptera, Cerambycidae, Lamiinae). Insecta Mundi 192:1-27.

Nearns, E. H. \& Tavakilian, G. L. 2012. New taxa and combinations in Onciderini Thomson, 1860 (Coleoptera, Cerambycidae, Lamiinae) from Central and South America, with notes on additional taxa. Insecta Mundi 231:1-26.

Nearns, E. H.; Lord, N. P. \& Miller, K. B. 2013. Oncid ID: Tool for Diagnosing Adult Twig Girdlers (Cerambycidae: Lamiinae: Onciderini). The University of New Mexico and Center for Plant Health Science and Technology, USDA, APHIS, PPQ. Disponível em $<$ http://cerambycids.com/oncidid/>. Acessado em 10 maio 2018.

Nearns, E. H.; Barclay, M. V. L. \& Tavakilian, G. L. 2014. Onciderini Thomson, 1860 (Coleoptera, Cerambycidae, Lamiinae) types of the Natural History Museum (BMNH). Zootaxa 3857(2):261-274.

Nearns, E. H. \& MaIER, C. A. 2016. Onciderini Thomson, 1860 (Coleoptera, Cerambycidae. Lamiinae) types of the Field Museum of Natural History $(\mathrm{FMNH})$, with a brief history of the Coleoptera collection. Insecta Mundi 494:1-7.

Nearns, E. H. \& Santos-Silva, A. 2016. Two new species of Onciderini Thomson, 1860 (Coleoptera, Cerambycidae, Lamiinae) from South America. Zootaxa 4137(3):445-450.

Nearns, E. H. \& Tavakilian, G. L. 2015. Onciderini Thomson, 1868 (Coleoptera, Cerambycidae, Lamiinae) types of the Muséum National d'Histoire Naturelle (MNHN) with a brief history of the Coleoptera collection. Insecta Mundi 459:1-47.

Strauch, A. 1861. Catalogue Systématique de tous les Coléoptères décrits dans les Annales de la Société Entomologique de France depuis 1832 jusqu'à $\mathbf{1 8 5 9}$. Halle, H. W. Schmidt, Libraire-Éditeur. $160 \mathrm{p}$.

Swift, I. P.; Bezark, L. G.; Nearns, E. H.; Solís, A. \& Hovore, F. T. 2010. Checklist of the Cerambycidae (Coleoptera) of Costa Rica. Insecta Mundi 131:1-68.

Tavakilian, G. L. 1996. Commentaire des planches. In: Hequet, V. Longicornes de Guyane. Cayenne, ORSTOM. 84p.

THOmson, J. 1868. Révision du groupe des oncidérites (Lamites, cérambycides, coléoptères). Physis Recueil d'Histoire Naturelle 2(5):41-92.

Thomson, J. 1878. Typi cerambycidarum Musei Thomsoniani. Paris, E. Deyrolle. 21p.

Turnbow, R. H.; Cave, R. D. \& Thomas, M. C. 2003. A list of the Cerambycidae of Honduras, with additions of previously unrecorded species. Ceiba 44(1):1-43.

VianA, M. J. 1972 Aporte al catálogo de Cerambycidae del Paraguay (Insecta, Coleoptera). Revista del Museo Argentino de Ciencias Naturales "Bernardino Rivadavia" 3(4):207-405.

Wappes, J. E.; Morris, R. F.; Nearns, E. H. \& Thomas, M. C. 2006. Preliminary list of Bolivian Cerambycidae (Coleoptera). Insecta Mundi 20(1-2):1-45. 